center experience with cervical mediastinoscopy: complications and false negative rate. Ann Thorac Surg. 2006;82:1185-9; discussion 1189-90.

http://dx.doi.org/10.1016/ j.jtcvs.2013.01.012

\section{IS INTRACAVITARY THORACOSCOPIC ULTRASONOGRAPHY REALLY NEEDED FOR EVERY INTRAPARENCHYMAL PULMONARY NODULE? \\ To the Editor:}

We read with interest the report by Khereba and colleagues, "'Thoracoscopic localization of intraparenchymal pulmonary nodules using direct intracavitary thoracoscopic ultrasonography prevents conversion of VATS procedures to thoracotomy in selected patients," which appeared in the November issue of the Journal. We congratulate Khereba and colleagues ${ }^{1}$ for their effort in clarifying the usefulness of this technique in practice of video-assisted thoracoscopic surgery (VATS) for localization of intraparenchymal pulmonary nodules; however, we want to share some significant concerns we had as we read their report.

Our first concern pertains to the indications for ultrasonography in patients with indeterminate pulmonary nodules. In the study of Khereba and colleagues, ${ }^{1} 27$ nodules were found not more than $1 \mathrm{~cm}$ distant from the pleura on computed tomographic scan. For these cases, we argue that they didn't really need ultrasonography to find a lesion just beneath the pleura, because direct visualization, palpation by finger, or a sliding method with an instrument might be helpful in localization of the target nodule, and most cases did not require any type of special localization method. ${ }^{2}$

Second, in 1 case there was an unidentifiable nodule with high probability of malignancy, and a thoracoscopic lobectomy was performed directly. Of course, thoracoscopic lobectomy is a standard procedure for unidentifiable nodules with high probability of malignancy. ${ }^{3}$ A thoracoscopic segmentectomy is also encouraging with curative purpose, because survival after thoracoscopic segmentectomy for small peripheral non-small cell lung cancer $(\leq 2 \mathrm{~cm})$ has been reported to be comparable to that after thoracoscopic lobectomy. ${ }^{4}$ In our practice, we have found direct segmentectomy to be an alternative method for management of those small and indeterminate peripheral pulmonary nodules, without the need to identify the precise location of the nodules by ultrasonography.

Third, Khereba and colleagues ${ }^{1}$ concluded that VATS ultrasonography prevented conversion to thoracotomy or lobectomy without tissue diagnosis in $43.5 \%$ of cases $(20 / 46)$. We argue that if precise location of the target nodule could not be confirmed, would the 20 cases all have needed to be converted to thoracotomy or lobectomy? In our practice of dealing with those so called "unidentifiable nodules," we haven't seen such a high conversion rate. Furthermore, even in the practice of lobectomy by VATS, the conversion rate was only $2.66 \%$ (11/414) in our group. ${ }^{5}$

We do agree with Khereba and colleagues $^{1}$ that intracavitary thoracoscopic ultrasonography could locate intrapulmonary nodules with high sensitivity and specificity. We believe, however, that just because intracavitary thoracoscopic ultrasonography is useful does not mean that it should be done in every case. The practical value of VATS ultrasonography appears excessively amplified.

Chengwu Liu, MD

Qiang $P u, M D$

Lunxu Liu, MD, PhD

Department of Thoracic Surgery

West China Hospital

Sichuan University Chengdu, China

\section{References}

1. Khereba M, Ferraro P, Duranceau A, Martin J, Goudie E, Thiffault V, et al. Thoracoscopic localization of intraparenchymal pulmonary nodules using direct intracavitary thoracoscopic ultrasonography prevents conversion of VATS procedures to thoracotomy in selected patients. $J$ Thorac Cardiovasc Surg. 2012;144:1160-5; discussion 1165-6.

2. Mattioli S, D’Ovidio F, Daddi N, Ferruzzi L, Pilotti V, Ruffato A, et al. Transthoracic endosonography for the intraoperative localization of lung nodules. Ann Thorac Surg. 2005;79(2): 443-8; discussion 448-9.

3. Yan TD, Black D, Bannon PG, McCaughan BC Systematic review and meta-analysis of randomized and nonrandomized trials on safety and efficacy of video-assisted thoracic surgery lobectomy for early-stage non-small-cell lung cancer. J Clin Oncol. 2009;27:2553-62.

4. Zhong C, Fang W, Mao T, Yao F, Chen W, Hu D. Comparison of thoracoscopic segmentectomy and thoracoscopic lobectomy for small-sized stage IA lung cancer. Ann Thorac Surg. 2012;94:362-7.

5. Mei J, Pu Q, Liao H, Ma L, Zhu Y, Liu L. A novel method for troubleshooting vascular injury during anatomic thoracoscopic pulmonary resection without conversion to thoracotomy. Surg Endosc. Jul 18, 2012 [Epub ahead of print].

http://dx.doi.org/10.1016/ j.jtcvs.2012.12.089

\section{Reply to the Editor:}

In our study, patients were recruited on the basis of the attending general thoracic surgeon's impression of difficulty in finding the nodules on reading the preoperative computed tomographic scan. Indeed, there were nodules not more than $1 \mathrm{~cm}$ from the visceral pleura; however, these nodules were chosen because of their small size or nonsolid nature (ground glass). Patients who had nodules that were believed to be easily found on thoracoscopy were not enrolled in the trial. In fact, a large proportion of video-assisted thoracoscopic surgical (VATS) wedge procedures performed during the study period were performed without the use of ultrasonography. We agree with the statement in the letter that "just because intracavitary ultrasonography is useful does not mean that it should be done in every case." We do not perform VATS with ultrasonography in all cases, only when we cannot find the nodule with standard techniques. 
Although we agree with the comment that VATS segmentectomy may be an alternative to VATS lobectomy in small peripheral lung cancers, this has not yet been definitively proven and is therefore not the standard of care for the surgical treatment of lung cancer in 2012. This is the subject of an ongoing Cancer and Leukemia Group B and National Cancer Institute randomized, multiinstitutional trial. We strongly encourage any center performing lung cancer surgery to enroll in this important and well-thought out trial (clinicaltrials. gov identifier NCT00499330; http:// www.clinicaltrials.gov/ct2/show/NCT 00499330 term =altorki\&rank=5).

The third comment is hard to answer, and I believe not well understood by Liu and colleagues themselves. We could not find the nodules by standard techniques in $43 \%$ of patients, and these nodules were then found by VATS with ultrasonography. The statement that we made in the article was not that if the nodules were unable to be found with standard techniques and a VATS lobectomy was chosen that the conversion rate to an open procedure would be high. In fact, our conversion rate from VATS lobectomy to open lobectomy is $\mathbf{1 \%}$. We were trying to make the point that if a nodule could not be found by standard VATS techniques, if VATS with ultrasonography had not been not available, a decision would have been required by the surgeon during the operation either to perform a thoracotomy and palpate the lung to wedge the nodule out for diagnosis or to perform a blind VATS lobectomy for tissue diagnosis. We do not know what would have actually happened in these cases, nor do we know the conversion rate from VATS to open procedures for these cases, because the nodules were indeed found with VATS with ultrasonography and therefore a VATS wedge resection was performed.

Moishe Liberman, MD, PhD CHUM Endoscopic Tracheobronchial and Oesophageal Center (CETOC)

Division of Thoracic Surgery

University of Montreal Montreal, Quebec, Canada

http://dx.doi.org/10.1016/ j.jtcvs.2013.01.013 